\author{
Лариса СОЛОГУБ, \\ orcid.org/0000-0001-9926-322X \\ кандидат філологічних наук, \\ дочент кафедри іноземних мов для природничих факультетів \\ Львівського національного університету імені Івана Франка \\ (Львів, Україна) larysa.solohub@lnu.edu.иa
}

\title{
«ЛІТЕРАТУРА ДЛЯ ЧАЙНИКІВ»: СТРУКТУРНО-ФУНКЦІОНАЛЬНІ ТА МОВНІ ОСОБЛИВОСТІ
}

\begin{abstract}
У статті представлено огляд наукових напрямів у дослідженні сучасного жанру «література для чайників» як жанру масової літератури в лінгвістиці, висвітлено його основні структурні ознаки. Жанр «література для чайників» - це жанр науково-популярного дискурсу, комунікативно спрямований на передачу адресантами теоретичних і практичних знань адресатам, які потрібні останнім для соиіалізації у суспільстві.

Дослідження здійснено на основі шести книг, присвячених розв'язанню психологічних проблем. 3'ясовано, що важливими компонентами структури сучасних творів є паратекстові елементи. представлені авторським (заголовок, присвята, авторська подяка, зміст, авторська передмова, предметний покажчик) $і$ видавничим паратекстом (видавнича анотація, подяка, довідка про автора), для яких характерні жорсткі канони побудови, які перетворюють визначені елементи у дієвий засіб прагматичного впливу. Внаслідок такого структурного членування реципієнт ефективніше сприймає подану інформацію. Кожна з композииійно-структурних частин книги має свої чітко окреслені иілі. Усі иці складники структури виконують єдину комунікативну мету досліджуваного жанру - апелюють до почуттів адресата, примушуючи його прочитати книгу та здобути певний теоретичний і практичний досвід, окреслюючи дидактичну орієнтацію жанру.

Для досягнення мети статті автори використовують різні мовні засоби, які зображають інформацію у сприйнятливій для адресата формі. На лексичному рівні спостерігається вжсивання іменників, прикметників i дієслів з певною семантикою, на морфолого-синтаксичному - дієслівні форми, дієслова у наказовому способi, модальні дієслова, односкладові та підрядні означальні речення. Використання видільних елементів (зміна шрифту) для маркування елементів структури дозволило адресанту зосередити увагу адресата на текстовій інформації.
\end{abstract}

Ключові слова: масова література, жанр, адресант, адресат, паратекстові елементи, прагматика, риторичні стратегіï.

Larysa SOLOHUB, orcid.org/0000-0001-9926-322X Candidate of Philological Sciences, Associate Professor at the Department of Foreign Language for Sciences Ivan Franko National University of Lviv (Lviv,Ukraine) larysa.solohub@lnu.edu.ua

\section{"LITERATURE FOR DUMMIES": STRUCTURAL, FUNCTIONAL AND LINGUISTIC FEATURES}

The article deals with the key structural features of modern genre "literature for dummies" as a genre of mass literature, shows researchers' opinions in regard to the problem of the given genre in modern linguistics. Genre "literature for dummies" is defined as a genre of scientific-popular discourse, the communicative aim of which is to spread addresser's knowledge to an addressee for their socialization in the society.

The research data in this article is drawn from six books related to a wide range of psychological problems. It turns out that the main structural components of the given genre are paratextual elements which are divided into author's (title, dedication, author's acknowledgements, table of context, author's introduction, index) and publisher's paratext (publisher's annotation, publisher's acknowledgements, about the author) with rigid structural forms which transforms defined elements into powerful pragmatic methods of influence on an addressee. Due to this structural division the recipient is able to fully comprehend the given information. Each of the structural elements works towards its own goal. All of these structural elements are subject to the main communicative purpose of the researched genre - appeal to the addressees' emotions forcing them to read the text and gain both theoretical and practical experience, thus determining its overall didactic orientation. 
To achieve the declared aim addressers use various linguistic structures, which present information in fully comprehensive form for an addressee. On the lexical level nouns, adjectives and verbs with the appropriate semantics are presented. On the morphological and syntactic levels we observe the usage of verbal forms, modal verbs, imperative constructions, one-member sentences and relative clauses. Using graphical forms, particularly fonts, to mark structural elements helps addressers focus addressees'attention on the textual information.

Key words: scientific-popular discourse, genre, addresser, addressee, paratextual elements, pragmatics, rhetorical strategies.

Постановка проблеми. Серія «для чайників» (“for dummies") з'явилася в США у 90-х роках XX ст., коли вийшла праця Дена Гукіна “DOS for Dummies" (1991 рік). Спочатку в серії виходили книжки з програмування, пізніше з'явилися праці, присвячені питанням природничих, суспільних і гуманітарних наук. На сайті видавництва John Wiley \& Sons, Inc., яке володіє цією франшизою, окреслено головний принцип вказаного жанру Content made easy означає зробити постулати науки легкими для сприйняття адресатом-нефахівцем. Нині цей жанр досягнув апогею свого розвитку та $\epsilon$ найпопулярнішою масовою літературою у світі. Ми визначаємо жанр «літератури для чайників» як жанр науково-популярного дискурсу, який реалізується у форматі книг, комунікативно спрямований на передачу знань адресату для набуття ним теоретичного та практичного досвіду. Питання відтворення жанрових особливостей «літератури для чайників» $є$ актуальним у сучасній лінгвістиці.

Аналіз досліджень. Розглядом проблем науково-популярної літератури займалися представники функціональної стилістики (М. М. Кожина, Н. М. Разінкіна, О. С. Троянська), дискурсознавства (В, І. Карасік, В. Є. Чернявська). Оскільки матеріалом для нашого дослідження слугували психологічні праці (self-help books), необхідно згадати наукові розвідки жанру «мистецтво успіху». Комунікативний аспект окресленого жанру потрапив до уваги австралійського вченого Дж. Коая (Коау, 2015). Українська дослідниця О. І. Багрій вивчала літературу, спрямовану на досягнення успіху у бізнесі, навчанні, фінансовому стані, сім’і (Багрій, 2011). Вивченню комунікативно-когнітивних засад мотиваційного жанру «мистецтво успіху» та виявленню особливостей їх репрезентації в англомовних працях присвятила своє дослідження Ю. Я. Годісь (Годісь, 2019).

Мета статті - визначити основні паратекстові компоненти загальної структури «літератури для чайників», дослідити й описати їх прагматичні функції та мовні особливості.

Виклад основного матеріалу. Структура текстів «літератури для чайників» складається 3 паратексту та основного тексту. Елементи пара- тексту (заголовок, довідка про автора, подяка, присвята, зміст, передмова, видавнича анотація, покажчик) межують із основним текстом (розділи та підрозділи), контролюють і скеровують читача на сприймання основного тексту. Зазначені елементи подаються у визначеному порядку та володіють типовими мовними маркерами вираження.

Авторський паратекст представлений заголовком, змістом, покажчиком, які виконують інформативну функцію, подякою та присвятою, головна функція якихполягаєвапелюваннідопочуттівадресата, та передмовою, яка закликає читача прочитати книгу та констатує авторитетність адресанта.

Заголовок (Title), виконуючи роль своєрідної реклами книги, орієнтує читача у просторі літератури i $\epsilon$ основою для прийняття читацького рішення ознайомитися чи не ознайомитися 3 працею автора (Яхонтова, 2009: 224) та, «слугуючи субститутом тексту у формальному аспекті» (Желтоногова, 2004), передає головну тему повідомлення. Задоволення інформаційних потреб адресата перетворює заголовок у дієвий засіб прагматичного впливу.

У проаналізованих творах назви праць представлені односкладовими реченнями 3 номінативними конструкціями Mindfulness for Dummies, Emotional Healing for Dummies, Meditation for Dummies, Dating for Dummies, Creative Visualization for Dummies, Mind Mapping for Dummies. Такі заголовки вирізняються більшою деталізованістю та інформативністю, що є ознакою наукового дискурсу.

Лише в чотирьох із шести проаналізованих праць присутня присвята (Dedication), тому можна стверджувати, що цей структурний елемент $є$ факультативним для цього жанру. Дедикацію виражено мовними формулами is dedicated to, for. У прикладі For Julie (Nixon) автор використовує адресну присвяту, виражену номінативною конструкцією, яка дозволяє стверджувати про високий рівень інтимізації в окресленому жанрі. Натомість в іншому фрагменті: "This book is dedicated to the great meditation masters and teachers in every culture and age, who continue to show us the way through their wise and compassionate example; and to you, dear reader. May the practice of meditation bring you the peace, health, and happiness you 
seek!" (Bodian) автор використовує безадресну присвяту, позиціонуючи себе як експерта 3 питань медитації. Звертання до адресата створює ілюзію піклування про реципієнта та сприяє завоюванню його довіри.

Висловлення подяки (Author's Acknowledgements) $є$ основною ознакою англомовного дискурсу, в якому автор дякує усім причетним до створення праці. У цьому паратекстовому фрагменті ми окреслюємо кілька семантичних блоків (колеги, друзі, родина), в яких акумулюється творчий процес адресанта від початку (ідеї) до кінцевого результату. Дж. Брауні порівнює процес написання книги із народженням дитини: "People who were when you were going through the labour saw you sweaty and cranky, and still stuck by you are much to be valued, and this group certainly qualifies (Brownie). I'd like to express my appreciation to the colleagues, teachers, and friends who contributed to the creation of this book" (Bodian). "Special thanks go to Sandra for sharing my excitement of the project, and providing many cups of tea while I spent evenings and weekends either practising mindfulness exercises, or staring intently at my laptop looking confused" (Alidina). За мовним критерієм на лексичному рівні спостерігаємо вживання іменників 3 семантикою «подяка» (appreciation, thanks), на граматичному рівні зауважуємо використання герундія на позначення типу подяки (sharing, providing) і підрядних означальних речень (who contributed to the creation of this book). Прагматичний вектор подяки спрямований на переконання адресата повірити в дієвість описаного методу та прочитати книгу.

3мicm (Table of Contents) - путівник на теренах книги, ключ до пошуку необхідних даних, оскільки в ньому представлено заголовки усіх частин, розділів і підрозділів із вказівкою на номери сторінок. Заголовки частин зі сторінками у змісті виділено жирним шрифтом і курсивом, тоді як заголовки розділів зі сторінками - лише жирним шрифтом, а заголовки підрозділів зі сторінками надруковано звичайним шрифтом. Таке використання видільних елементів в аранжуванні тексту при переході від загального до конкретного сприяє концентрації уваги адресата на текстовій інформації. Розглянемо такий фрагмент:

\section{Introduction 1}

Part 1: Introducing Mindfulness 5

Chapter 1: Discovering Mindfulness 7

Understanding the Meaning of Mindfulness 8

Looking at Mindfulness Meditation 9

Using Mindfulness to Help You 10

Allowing space to heal 11
Enjoying greater relaxation 12

Improving productivity 12

Exploring for personal discovery 13

Starting the Mindfulness 15

Beginning the voyage 15

Overcoming challenges 16

Exploring the journey of a lifetime 17

(Alidina)

У наведеному вище прикладі всі заголовки представлені віддієслівними заголовками, в яких ядерним компонентом виступає герундій (Introducing Mindfulness $\rightarrow$ Discovering Mindfulness $\rightarrow$ Starting the Mindfulness $\rightarrow$ Exploring the journey of a lifetime). Такі заголовки вирізняються певним динамізмом, допомагають адресантові наголосити на процесуальності інформації, що ставить автора і читача на одну площину.

Авторська передмова (Introduction) - стисла характеристика праці обсягом до шести сторінок, розміщена у препозиції до основного тексту, прагматична мета якої полягає в інформуванні адресата про важливість представленої інформації, формулюванні основних принципів окресленої тематики, показі характерних особливостей книги. Беручи до уваги типові риторичні кроки та стратегії для інтерпретації жанру, запропоновані в популярній моделі Дж. Свейлза (Swales, 1990), ми, як і Ю. Я. Годісь, виділяємо такі риторичні стратегії авторської передмови: формулювання мети, апелювання до власного досвіду, аранжування книги, заклик до прочитання книги (Годісь, 2019:88-92).Розглянемодетальнішекожнустратегію.

Формулювання мети - окреслення основних постулатів книги. This book's main aim is to get you started on the road to bringing creative visualization into your life (Nixon). In this book you can discover how to re-ignite your perception of this mystery called life... Mindfulness for Dummies provides you with the tools to practice mindfulness of your own (Alidina). Підкреслені елементи є формульними маркерами вираження мети. Використання особового займенника уоu та похідного уоur у наведених вище прикладах є потужним засобом створення інтимізації у передмовах. Адже те, що збирається прочитати адресат, - це система знань, яка допоможе йому в майбутньому (Годісь, 2019: 99).

Апелювання до власного досвіду актуалізується через опис комунікативної ситуації. Так, ознайомившись із наступним фрагментом, адресат дізнається, що автор почав замислюватися над питанням самоусвідомлення ще в дитинстві, а з віком поглибив свої знання: "When I was about eight years old, I discovered an amazing fact - I'm actually alive, on this planet, in this universe! As 
I grew up, I began to lose my grip on this sense of wonder until I stumbled upon mindfulness and a range of philosophers. I continue to enjoy asking the big questions, and find that mindfulness beautifully compliments my natural tendency to be philosophical". Таке вкраплення в текст налаштовує адресата на довіру до адресанта.

Аранжування книги (How This Book is Organised) окреслює основне завдання кожного розділу книги, наприклад, Part III: Setting Up the Date (You've met someone, you think you click, and now you're at the next step: setting up the date. In Part III, you can find surefire tips on how to ask for a date so that you get the answer you want or, if the answer is no, so you can bow out gracefully, with your dignity intact; how to deal with the potentially sticky situation of getting (or giving out) a phone number; and what to look for in the place you pick for the date) (Brownie) та перелік символів, які використовуються у книзі (Icons Used in This Book).

Детальне вивчення риторичної стратегії заклику до прочитання книги засвідчило, що автори через чітке формулювання мети книги мотивують читача ознайомитися 3 книгою, після чого він набуде неоціненного теоретичного та практичного досвіду: “After you've read this book, I believe that you're going to realise better than ever that the world is truly your oyster and that you can achieve your goals when you put mind to it. Now go out and enjoy life to the full!" (Nixon). У цьому фрагменті вказана стратегія реалізується через наказовий спосіб із рекомендаційним значенням, модальне дієслово сап використовується 3 семантикою «спроможності виконання дії», вживаються дієслова із семантикою «виконання дії» (realise, achieve).

Предметний покажчик, укладений за алфавітом (Index), є допоміжним матеріалом. У ньому представлені ключові поняття певної галузі зі сторінками, які дозволяють адресатові орієнтуватися в предметному просторі.

journaling

by children, 302

Dream Diary, 82

Eating Habits Observation Log, 60-61

emotions, 45-46, 47

gratitude diary, 280

identifying mood-raising experiences, 53

listing peaceful places, 95

morning free-writing, 323

after rejection, 180

judgement. See also criticism

about your childhood, avoiding, 112-113

perfectionism leading to, 205-206 releasing grievances, 162-164

stopping, 220

transforming judgemental thoughts, 206 (Beales).

Прагматичний вектор предметного покажчика спрямований наконкретизаціюпошуку, зменшення або уникнення «інформаційного шуму», забезпечуючи задоволення інформаційних потреб читача.

Крім авторського паратексту, в «літературі для чайників» присутній і видавничий паратекст, який представлений видавничою анотацією, подякою та довідкою про автора. Рекламна функція цих паратекстових елементів дозволяє видавництву окреслити місце твору на ринку друкованої продукції та закликати потенційного адресата до прочитання праці.

Прагматичний вектор довідки про автора (About the Author) спрямований на надання адресатові уявлення про особистість адресанта, будуючи в його свідомості авторитетність останнього та сприяючи внутрішній діалогізації між автором і читачем. Florian Rustler is an innovation coach working at international level and the founder of creaffective. As a process moderator he presents a strategy and innovation workshops in German, English and mandarin Chinese to help his clients produce new solutions quickly; for example, when developing new products and services. As a tutor he teaches organisations the processes and techniques of creative problem solving and assists them with generating an innovation culture. He learned Mind Mapping while still at school. A teacher introduced the technique in just ten minutes during class but then took it no further. However, Florian didn't let these ten minutes go to waste. He got hold of Tony Buzan's book on Mind Mapping, the only one available at the time, and subsequently applied the technique. He later qualified as a Mind Mapping tutor and since then has given hundreds of Mind Mapping classes and published an online Mind Mapping course (Rusler). $\mathrm{y}$ наведеному фрагменті імпліцитно представлено два комунікативні блоки (професійна діяльність на освіта), які визначають адресанта як професіонала у галузі створення асоціативних карт.

Також у цьому жанрі ми спостерігаємо видавничу подяку (Publisher's Acknowledgements), у якій видавець дякує за підготовку до видання книги. We're proud of this book, please send us your comments through our Dummies online registration form located at www.dummies.com/register/ (заклик до зворотнього зв'язку).

Some of the people who helped bring this book to the market include the following:

Composition Services

Project Coordinator: Lynsey Stanford 
Proofreader: Lauren Mandelbaum

Indexer: Christine Karpeles (Alidina)

$\mathrm{У}$ постпозиції до основного твору розташована видавнича (промочійна) анотація (укладена видавцем стисла характеристика твору стосовно його змісту, жанру, цільового призначення). Прагматична функція цього паратекстового компоненту полягає в зацікавленні читача твором через інформування про його зміст та особливості. Оскільки промоційна анотація належить до «колонізованих» рекламою гібридних жанрів (Bhatia, 2004), то в ній присутній широкий спектр елементів рекламного дискурсу. Розглянемо такий приклад:

Face your emotions head on and take control of your life

How many times have you said 'I'm fine!', when really you not? Bottling up emotions can wear out your body, damaging your physical appearance and internal organs as well as limiting the way you think and communicate. This expert toolkit contains all the strategies you need to recognise and resolve harmful emotional states, leavingyou physically and mentally ready to face present and future challenges with confidence.

- Discover the basics - explore the physiology of emotions and how emotional trauma can result in lasting physical symptoms.

- Tune into your body - revamp your diet, exercise, breathing and sleep patterns to help create inner calm.

- Put your feelings into context - map out your emotional history, resolve lingering issues and learn to focus on the positive.

- Heal yourself - practice mindfulness, motivate yourself to change and free your creative spirit.

- Look ahead - identify long-term challenges and plan ways to help yourself and others deal with difficult emotions.

'Emotional experiences, like it or not, always form emotional scars, but this book goes a long way to making them a lot less painful. Full of kindness, com- passion, good sense, facts and intelligent strategies, this truly helpful guide leaves most self-help books far behind'.

- Virginia Ironside, Agony Aunt at The Independent. (Beales)

Заголовок цієї промоційної анотації містить головну мету анотованої книги. Використання питального речення збуджує інтерес адресата, оскільки, окрім привертання його уваги, воно інтригує читача, імітуючи діалог між видавцем i читачем. Варто зазначити, що відразу після запитання видавець подає відповідь, яка імпліцитно містить позитивну оцінку книги. Використання імперативних конструкцій, яке носить радше рекомендаційний характер, помітно скорочує комунікативну дистанцію між видавцем і читачем, що сприяє внутрішній інтимізації окресленого жанру. Також ми спостерігаємо апелювання до авторитету, коли видавець підсилює свою анотацію цитатою. Таке вкраплення методом навіювання за допомогою меліоративної лексики (kindness, compassion, good sense, intelligent strategies, helpful guide) посилює інтерес читача до книги та бажання прочитати іiі.

Висновки. Таким чином, зовнішня структура «літератури для чайників» $є$ жорстко регламентованою. Прагматичний вектор паратекстуальних складників скерований на досягнення головної комунікативної мети окресленого жанру - апелювання до почуттів адресата, примушуючи його прочитати книгу та здобути теоретичний $\mathrm{i}$ практичний досвід. Використання адресантом певних лексичних (меліоративної лексики, дієслів із відповідною семантикою), морфологічних (наказового способу дієслова, дієслівних форм, модальних дієслів) і синтаксичних (односкладових, підрядних речень) форм сприяє окресленню прагматичних функцій складників зовнішньої структури досліджуваного жанру.

\section{СПИСОК ВИКОРИСТАНИХ ДЖЕРЕЛ}

1. Багрій О. І. Тексти популярної психології: жанрові та прагмариторичні характеристики. Вісник Харківського наџіонального університету імені В. Н. Каразіна. Романо-германська філологія. Методика викладання іноземних мов. Харків, 2011б. Вип. 67 (972). С. 138-144.

2. Годісь Ю. Я. Комунікативно-когнітивні засади мотиваційного жанру «мистецтво успіху» (на матеріалі англомовних текстів) : дис. канд. філ. наук: 10.02.04. Львів, 2019. 253 с.

3. Желтоногова Т. В. Заголовок як компонент структури українського поетичного тексту : автореф. дис. ... канд. філол. наук: 10.02.01. Кіровоград, 2004. 19 с.

4. Карасик В. И. Языковой круг: личность, концепты, дискурс. Волгоград : Перемена, 2002. 477 с.

5. Кожина М. Н. О диалогичности письменной научной речи : учеб. пособие. Пермь : Изд-во Пермского гос. ун-та, 1986. $92 \mathrm{c}$.

6. Разинкина Н. М. Стилистика английской научной речи. Москва : Наука, 1972. 168 с.

7. Троянская Е. С. Лингвостилистическое исследование немецкой научной литературы. Москва : Наука, 1982.312 с.

8. Чернявская В. Е. Интерпретация научного текста: стиль, текст, дискурс. Москва : URSS, 2007. 127 с.

9. Яхонтова Т. В. Лінгвістична генологія наукової комунікації : монографія. Львів : Видавничий центр ЛНУ імені Івана Франка, 2009. 420 с. 
10. Bhatia V. Analyzing genre: Language use in professional settings. London : Longman, 1993. 184 p.

11. Koay D. L. Self-improvement books: a Genre Analysis. A Thesis for the degree of PhD in Applied Linguistics. Victoria University of Wellington, 2015. 356 p.

12. Swales J. Genre analysis: english in academic and research settings. Cambridge : Cambridge University Press, 1990.260p.

\section{ІЛЮСТРАТИВНІ ДЖЕРЕЛА}

1. Alidina Sh. Mindfulness for Dummies. Chichester, John Wiley \& Sons, Ltd, 2010. 312 p.

2. Beales D., Whitten H. Emotional Healing for Dummies. Chichester, John Wiley \& Sons, Ltd, 2010. 352 p.

3. Bodian S. Meditation for Dummies. $2^{\text {nd }}$ ed. Indianapolis, Wiley Publishing, Inc., 2006. 360 p.

4. Browne J. Dating for Dummies. $2^{\text {nd }}$ ed. Indianapolis, Wiley Publishing, Inc., 2006. 408 p.

5. Nixon R. Creative Visualization for Dummies. Chichester, John Wiley \& Sons, Ltd, 2011. 376 p.

6. Rustler F. Mind Mapping for Dummies. Chichester, John Wiley \& Sons, Ltd, 2012. 238 p.

\section{REFERENCES}

1. Bahriy O. I. Teksty populiarnii psyholohii: janrovi i pragmarytorychni osoblyvosti [Texts of popular psychology: generic and pragmarhetoric features]. Bulletin of Kharkiv National University. Roman-Germanic Philology. Methodology of Teaching Foreign Languages. 2011b. Vol. 67 (972). P. 138-144 [in Ukrainian].

2. Godis Yu. Ya. Komunikatyvno-kognityvni zasady motyvatsiinoho janru "mystetsvo uspihu" (na materiali anglomovnyh tekstiv) [Communicative and cognitive aspects of the motivational success genre (based on English-language texts)]: PhD Thesis. Lviv, 2019. 253 p. [in Ukrainian].

3. Zhentonohova T. V. Zaholovok yak komponent struktury ukraiinskoho poetychnoho tekstu [Title as a component of structure of Ukranian poetic text]: PhD Thesis, 2004. 19 p. [in Ukranian].

4. Karasik V. I. Yazykovoi krug: lichnost, kontsepty, diskurs [Language circle: human, concepts, discourse]. Volgograd : Peremena, 2002. 477 p. [in Russian].

5. Kozhyna M. N. O dialogichnosti pismennoi nauchnoi rechi : ucheb. posobie [On dialogism of written scientific communication : textbook]. Perm. Publishing House of Perm University, 1986. 92 p. [in Russian].

6. Razinkina N. M. Stilistika angliiskoi nauchnoi rechi [Stylistics of English scientific communication]. Moscow : Nauka, 1972. 168 p. [in Russian].

7. Troyanskaya E. S. Lingvostilisticheskoe issledovanie nemetskoi nauchnoi literatury [Linguistic stylistic research on German scientific literature]. Moscow : Nauka, 1982. 312 p. [in Russian].

8. Chernyavskaya V. E. Interpretatsiia nauchnogo teksta: stil, text, diskurs [Interpretation of scientific text: style, text, discourse]. Moscow : URSS, 2007. 127 p. [in Russian].

9. Yakhontova T. V. Lingvistychna genologiia naukovoii komunikatsii : monographia [Linguistic genology of scientific communication : monograph]. Lviv, Publishing House of LNU, 2009. 420 p. [in Ukrainian].

10. Bhatia V. Analyzing genre: Language use in professional settings. London : Longman, 1993. 184 p.

11. Koay D. L. Self-improvement books: a Genre Analysis. A Thesis for the degree of PhD in Applied Linguistics. Victoria University of Wellington, 2015. 356 p.

12. Swales J. Genre analysis: english in academic and research settings. Cambridge : Cambridge University Press, 1990. $260 \mathrm{p}$.

\section{ILLUSTRATIVE SOURCES}

1. Alidina Sh. Mindfulness for Dummies. Chichester, John Wiley \& Sons, Ltd, 2010. 312 p.

2. Beales D., Whitten H. Emotional Healing for Dummies. Chichester, John Wiley \& Sons, Ltd, 2010. 352 p.

3. Bodian S. Meditation for Dummies. $2^{\text {nd }}$ ed. Indianapolis, Wiley Publishing, Inc., 2006. 360 p.

4. Browne J. Dating for Dummies. $2^{\text {nd }}$ ed. Indianapolis, Wiley Publishing, Inc., 2006. 408 p.

5. Nixon R. Creative Visualization for Dummies. Chichester, John Wiley \& Sons, Ltd, 2011. 376 p.

6. Rustler F. Mind Mapping for Dummies. Chichester, John Wiley \& Sons, Ltd, 2012. 238 p. 